\title{
Presentism, Truthmaking and Necessary Connections ${ }^{1}$
}

Abstract:

Ross Cameron puts forward a novel solution to the truthmaker problem facing presentism (sect. 1). I claim that, by Cameron's own lights (explained in sect. 2), the view is not in fact a presentist view at all, but rather requires us to endorse a form of Priority Presentism, whereby past objects are derivative and depend for their existence upon present objects. I argue (sect. 3 and 4 ) that this view should be rejected.

1. Introduction

Cameron $(2011,2013)$ puts forward a novel solution to the truthmaker objection facing presentism. The objection is well-known; I shall only sketch it here. Truths require truthmakers - existing entities that make propositions true. ${ }^{2}$ There are true propositions about the past. According to presentists, there are no past objects (for only present objects exist). The tension between these three principles mitigates against presentism - at least, so say opponents of presentism. Whilst it's far from clear that presentists should see this as an argument against presentism (as opposed to, for instance, an argument against truthmakers being required for all true propositions (see, inter alia, Merricks (2007), Sanson and Caplan, (2010), Tallant $(2009,2010))$, some presentists have tried to sooth the tension by providing presently existing truthmakers for truths about the past.

As I say, my focus in this paper is a proposal by Ross Cameron. Cameron claims that what makes-true propositions about the past is that objects currently instantiate what he calls 'temporal distributional properties'. The notion of a temporal distributional property is central and requires a little unpacking. Let me start with the notion of a spatial distributional property, as explicated by Parsons (2004).

Consider a domino. Its surface is polkadotted. A natural way to analyse this is via the domino instantiating different colour properties at different locations along its surface. A different way to analyse this is via the domino instantiating a single distributional property: 'being polkadotted'. The distributional property just described is spatial, in that it distributes across a spatial region. It is in virtue of instantiating this property that the domino has the appearance that it does.

In contrast, Cameron offers us a Temporal Distributional property. Borrowing from Tallant and Ingram (2012a), call these 'TDPs'. An example of a TDP is: being-a-boy-then-being-a-man-thenbeing-a-pensioner. In addition to TDPs, Cameron argues that every object instantiates an age property. The age property is intended to pick out how far along the TDP we are. ${ }^{3}$ So, if Cameron instantiated the TDP described above and the age property of being 1, then he would presently be a boy. If Cameron instantiated the TDP described above and the age property of being 2, then he would presently be a man-and so on.

To see these how these properties solve the truthmaker problem, consider the following (vastly simplified) example. ${ }^{4}$ Let us say that Cameron is now a man and that he was a boy. On Cameron's metaphysic, that requires that Cameron instantiate the property being-a-boy-then-being-a-man-thenbeing-a-pensioner and the age property of being 2 . Notice, then, that between them the age property

\footnotetext{
${ }^{1}$ Many thanks to two referees for this journal for comments on a previous draft.

${ }^{2}$ What 'making' consists in is a little controversial. I don't discuss the matter here, but see Armstrong (2004: 57), Liggins (2005) and Schaffer (2010) for representative discussions.

${ }^{3}$ In what follows I assume that being age 1 indicates that the first portion of the TDP is present; being 2 indicates that the second portion of the TDP is present-and so on.

${ }^{4}$ The claim that this allows Cameron to 'solve' the truthmaker problem may be much too quick: The truthmaker problem isn't just that we can't come up with truthmakers - suitable entities can always be posited ad hoc. The heart of the problem is that there are no plausible/independently motivated/etc. objects to serve as truthmakers for truths about the past. To say that Cameron has solved this problem is to establish that his posits are plausible and independently motivated, which this brief discussion does not motivate. For scepticism about the solution, see Tallant and Ingram (2012a; 2012b).
} 
and the TDP not only serve to fix how Cameron is now, they also serve to fix how he was. Namely: he was a boy. In that case, the union of the TDP and age property serve to make it true that $<$ Cameron was a boy>, and so we have a solution to the truthmaker problem. ${ }^{5}$ So far, so good. But there are problems in the offing. These problems lead me to argue that Cameron's view should be rejected.

\section{Meta-ontology}

Cameron has a distinctive approach to meta-ontology. There are two particular aspects of this approach that I want to bring out: an account of the distinction between the fundamental and the derivative, and a view on how to account for acceptable necessary connections via ontological dependence (and analysis of this form of dependence). I take these points in turn.

2.1 The fundamental and the derivative

In a number of places, Cameron (e.g. 2008) introduces a distinction between fundamental objects and merely derivative ones.

The rules of the language are that 'a really (or fundamentally) exists' is true iff a is an element of our ontology (read: iff a does some truthmaking); that 'a exists' is true iff <a exists> is made true by some thing(s); and that 'a merely (or derivatively) exists' is true iff $<$ a exists $>$ is made true but isn't made true by a. (2008: 7)

To give an example of how this is supposed to work, consider the debate surrounding Van Inwagen's (1990) Special Composition Question, that asks 'when does composition occur?'. According to the view taken by the mereological nihilist, composition never occurs. There are no composite objects. In contrast, according to the universalist, there exists a composite object composed of $\mathrm{x}$ and $\mathrm{y}$, whenever $\mathrm{x}$ and $\mathrm{y}$ exist. Cameron proposes a different line.

The thought is that the objects themselves are enough to make it true that there is a sum of those objects. If <a exists> might be made true by some thing(s) other than a then <the sum of $\mathrm{a}, \mathrm{b}$ and $\mathrm{c}$ exists> might be made true by some thing(s) other than the sum of $\mathrm{a}, \mathrm{b}$ and $\mathrm{c}$ : it might simply be made true by a, b and c. Since the ontological commitments of a theory are what's needed to make the sentences of that theory true, it follows that a theory can contain the sentence 'the sum of $a, b$ and $c$ exists' without being ontologically committed to such a sum-it might only be committed to $\mathrm{a}, \mathrm{b}$ and $\mathrm{c}$. So the universalist might be right about what sentences are true - for any collection of objects it might be true to say that there is a sum of those objects; but the nihilist might be right about what there is - the only things we are committed to in order to make the universalist's sentences true are simples. (2008: 5)

Abstracted away from the case involving composition, the thesis amounts to this:

The claim that some propositions of the form $<\mathrm{X}$ exists $>$ can be made true by something other than $\mathrm{X}$ leads us to the distinction between derivative and fundamental reality: what there is and what there really is. If $X$ is needed as the truthmaker for $\langle X$ exists $>$ then $X$ really existsit is part of fundamental reality. But if $\langle\mathrm{X}$ exists $>$ is made true not by $\mathrm{X}$ but by $\mathrm{Y}$ then, while $\mathrm{X}$ exists, $\mathrm{X}$ does not really exist: it is $\mathrm{Y}$ that really exists; it is $\mathrm{Y}$ that is part of fundamental ontology, and which is the ontological commitment of <X exists>. (2008: 17)

I don't mean to raise an objection (here) to this view of meta-ontology. What concerns me, as we shall see in section 3, is what happens when we conjoin it to the view of presentism and truthmaking noted above.

\subsection{Necessary connections}

\footnotetext{
${ }^{5}$ In fact, things are a little more complex. To account for truths such as <there were dinosaurs> Cameron must locate a presently existing bearer of TDPs. This he does, in the form of the world (2011: 66). I will follow Cameron's example in restricting the general discussion to easier cases (such as $<$ Ross was a child $>$ ).
} 
We now need to consider the second aspect of Cameron's meta-ontology. Some necessary connections that one might posit seem worrisome (at least, so goes the orthodoxy). Although we may think that my dropping the pen causes it to fall, it seems altogether too strong to say that my dropping the pen necessitates its falling. In contrast, some necessary connections seem benign. If s exists, then necessarily so does the singleton set of $\mathrm{s}$.

Cameron (2008: 7-11) offers a way of diagnosing what the difference consists in and also of explaining why the benign necessary connections are non-threatening. Benign necessary connections between two propositions $\langle\mathrm{p}\rangle$ and $\langle\mathrm{q}\rangle$ are to be explained by virtue of $\langle\mathrm{p}\rangle$ and $\langle\mathrm{q}\rangle$ having the same truthmaker. Thus, $<\mathrm{s}$ exists $>$ and $<\{\mathrm{s}\}$ exists $>$ are both made true by $\mathrm{s}$. There is nothing mysterious about this connection. Suppose that we think of Socrates and the singleton set $\{$ Socrates $\}$, then

we also have a nice explanation of the necessary connection the other way-one that doesn't require us to invoke the mysterious relation of ontological dependence; $<$ Socrates' singleton exists> entails < Socrates Exists> not because of any mysterious relation of dependency holding between Socrates and his singleton but simply because the only possible truthmaker of $<$ Socrates' singleton exists $>$ is Socrates. And that's not some mysterious modal connection, it's just a consequence of how we use the term 'Socrates' singleton'. We only count $<$ Socrates' singleton exists $>$ as true in worlds where Socrates is there to make it true. Since Socrates makes it true that Socrates exists, we have an explanation of why $<$ Socrates' singleton exists $>$ can't be true without $<$ Socrates exists $>$ being true. (Cameron, 2008: 10)

As Cameron (2010b: 184) notes, this is to use truthmaker theory to give us an analysis of ontological dependence (a point that will become important in a moment); crucially, an analysis of ontological dependence that is free of mysterious and unexplained modal connections.

In contrast, suppose that I posit a necessary connection between the dropping of my pen and its falling. This connection seems really rather mysterious. Combinatorial reasoning at least seems to suggest that we have free-recombination among distinct elements of our ontology (Cf. Cameron 2008: 8 ), and, in that case, it ought to be possible that I release the pen without its falling. It is also not the case that the truthmaker for <I dropped the pen> is the same as the truthmaker for <the pen is falling $>$ - at least, not according to any picture according to which this would be a necessary connection between distinct particulars.

Thus, we have an explanation of the difference between benign and problematic necessary connections and an explanation of why benign necessary connections are not mysterious unlike their objectionable cousins. With these pieces of Cameron's meta-ontology in place, let me now explain why Cameron's presentist project will not succeed.

\section{This is not presentism (and it's a bad view even if it is)}

Recall Cameron's distinction between the fundamental and the derivative. But now, note the following: the truthmaker for <there were Xs> is not a past $\mathrm{x}$. Rather, the truthmaker for <there were $\mathrm{Xs}>$ is a presently existing TDP, coupled to the property of age. Thus, the proposition <there were $\mathrm{Xs}>$ is made true by something other than X's being past. In that case, I think, $\mathrm{X}$ 's being past should be regarded as a derivative existent. There are some concerns with the argument, so presented, and I'll return to them in section 4 .

\subsection{Not Presentism}

For now, however, suppose that everything that I've said so far is right. Past objects turn out to be merely derivative and depend upon the present objects for their existence- - for the truthmakers for $<$ there were Xs> are not the Xs themselves. Rather, the truthmakers for <there were Xs> are Ys (presently existing TDPs and present age properties). Where we have such an arrangement, recall (2.1), we have ontological dependence. 
Now Presentism is (usually) defined as the thesis that 'only present objects exist'. ${ }^{6}$ Since, as we have just seen, Cameron's position seems to commit us to the existence of past objects - albeit only past derivative objects - it would appear that Cameron's view is not presentist. After all, there are nonpresent objects.

Now there is an obvious reply to this. The view that the present is fundamental and the past merely derivative might just be treated as a version of presentism. Indeed, precisely this view is flirted with by Baron (2012) as a form of 'Priority Presentism'. Baron himself rejects the view (there, though he endorses it in his 2014), but certainly regards it as a species of presentism. Might we not do the same? After all, in saying that Cameron's view isn't really a form of presentism, we're engaging in some kind of verbal dispute about which views get to count as presentist. It's far from clear that anything substantial turns on the issue. In what follows I suggest we should not treat Cameron's view as a version of presentism precisely because it requires us to make claims that presentists should want to resist.

\subsection{A bad view}

I think that presentists should reject this Priority Presentism. There is a well-known argument against non-presentist views that, I think, afflicts Priority Presentism. In what follows, I offer a brief application of the problem to the Priority Presentist view. The problem itself is well-known in the wider literature, and is often describe by the question 'how can I know that I am now, now?'.

Here is my short application of this problem to Priority Presentism. Consider a sentence token, U, 'I am present'. All people — past, present or future — believe instances of $U$ to be true; we all believe that we are present. According to Priority Presentism, there exist derivative, past people - for <there were people> is true. If there exist past people, then (since those people are past), they falsely believe that $<\mathrm{I}$ am present $>$ of themselves. Since there are many more people at past-times than there are at present-times, it follows that the vast majority of people falsely believe of themselves that $<\mathrm{I}$ am present>. To closely paraphrase, Button (2006: 3131): contemporary Priority Presentists have all the same evidence for thinking that they are present as their merely derivative predecessors did. ${ }^{8}$ By induction on the errors of their predecessors, Priority Presentists are almost certainly mistaken in their central claim that they are present. In the face of this induction, we should relinquish our own beliefs that $<\mathrm{I}$ am present $>$. But this is absurd. We cannot give up on this belief. And so we must give up on the Priority Presentism that leads us to this conclusion.

Now the presentist is supposed to have any easy time of it. Whenever someone is present, and forms the judgment $<\mathrm{I}$ am present $>$, they are correct. We thus cannot generate the base for the sceptical induction, if we adopt normal versions of presentism. There is simply no room for this just-described kind of sceptical doubt to creep in.

But, as we have seen, Cameron (and the Priority Presentist) cannot have so easy a time of matters. After all, past people exist, even if they are only derivative; and past people will form the judgment that $<\mathrm{I}$ am present $>$. In that case, the merely derivative people are wrong. In that case, of course, the presentist should not endorse Priority Presentism.

(Baron (2014) offers a reply to the problem for the Priority Presentist, but I do not find it convincing. As I have presented the problem - borrowing from Button (2006), who borrows from Bourne (2002) - the concern is whether or not people know that they are present; both Bourne and Button say that they do not. Button and Bourne derive this conclusion via a sceptical induction. As Baron (2014: 19) sees the problem, however, it is that past people are not (and I quote) 'where the action is'.

\footnotetext{
${ }^{6}$ See, inter alia, Crisp (2004) and Markosian (2004). For a slightly different view, see Tallant (2014).

${ }^{7}$ The problem was introduced-independently_by Bradon-Mitchell (2004) and Bourne (2002). For a recent defence of the problem see Tallant (2011). My presentation here is a short-sketch of the full problem.

${ }^{8}$ Of course, Button (2006) does not think the sceptical problem to be pressing. See Tallant (2011) for reasons to disagree.
} 
Baron's claim is that what is at issue in the argument is that past people are somehow too far removed from the present, and presentness itself. This is something that Baron claims Priority Presentism ameliorates by grounding the non-present in the present. Because Baron and I see the problem so very differently - I see it as a sceptical problem arising from the falsity of a great number of beliefs; he sees it to do with 'not being where the action is'-it's hard to see that Baron has solved the problem identified here, and discussed by Bourne, Bradon-Mitchell, Button and myself. At the very least, I think, more needs to be said by Baron and other Priority Presentists about how being 'where the action is' deals with what is, at heart, a sceptical induction).

\subsection{A really bad view}

In fact, things will get even worse for the Priority Presentist taking Cameron's route. As noted already, a key step in the argument in favour of presentism is that the A-theory of time is our intuitive theory of time. Some presentists will in fact go a little further and simply claim that presentism itself is our most intuitive view of time - the commonsense view of the person on the street (though they do so without ever providing any evidence to support that claim). ${ }^{9}$

But on the Priority Presentism to which Cameron is committed by his meta-ontological position, we find ourselves presented with a most counter-intuitive view. As Baron (2012: 17) points out, to the extent that there is any intuition at all about ontological dependence as it spans times, it is the present that depends upon the past — rather than the other way around. Where it sounds passably intuitive to say that the way that things are depends upon the way things were, it sounds baroque to claim that the way that things were depends upon the way things are. ${ }^{10}$ But, as we have seen, Cameron's analysis of ontological dependence is being used to give us a distinction between the fundamental and the derivative. Once coupled to his TDPs, this leads us to the conclusion that the past depends upon the present. That this is so counterintuitive does enough to block any intuitive lure that presentism may have and, to that end, further undermines any motivations for being a presentist. No presentist should be a Cameron-style Priority Presentist.

\section{Derivative?}

In this section of the paper I want to consider two potential responses from Cameron. The first looks to argue that the argument I presented in section 3 is invalid (4.1). The second response considers the general matter of what happens if Cameron can show that past objects are not derivative.

\subsection{Reviewing the argument}

In section 3 I ran (roughly) the following argument.

1. Cameron says that: 'a merely (or derivatively) exists' is true iff <a exists> is made true, but isn't made true by a'

2. <there were dinosaurs> is true, but isn't made true by the existence of dinosaurs

3. Therefore, there are derivative dinosaurs

Clearly, as presented the argument is invalid: the proposition <there were dinosaurs $>$ is not of the form <a exists>. And in that case, there is no objection to Cameron.

My response: in part, the reason for stating the argument this way was stylistic; much of the debate revolves around whether it's true that <there were dinosaurs> and so I chose the example for the sake of holding fixed the example. But I don't think that it's at all hard to see that there will be cases that

\footnotetext{
${ }^{9}$ See, inter alia, Bigelow (1996) and Markosian (2004).

${ }^{10}$ Of course, the Priority Presentist might take Baron's (2014: 17) route and try to explain away the intuition. I don't find this terribly convincing, as, even in spite of the explanation that Baron offers-in short, that we mistake the direction of ontological dependence for the direction of causal influence - I still find priority presentism objectionable. That is: Baron's explanation does not seem to succeed in explaining away $m y$ intuitions. Contra Baron, I don't think that I'm mistaking ontological dependence for causation, but it still seems intuitively objectionable to have dependencies running in these directions.
} 
we could supplement for (2) and that would give rise to the problem. For instance, it's true that <there are many important historical events for us to study in a History Degree> (the First World War; the Second World War, etc.). For that to be true, it must be true that <there are historical events>. In turn, this entails that <there exist historical events>. (Notice: it doesn't matter whether Cameron gives an analysis of <there are historical facts >: his perfectly general meta-ontological point is that where a true claim of the form <there is an $\mathrm{x}>$ is made true by something other than $\mathrm{x}, \mathrm{x}$ is a merely derivative existent. In that case, the First World War exists, but is merely derivative.) Of course, such historical events won't be fundamental by Cameron's lights. They will be merely derivative and will depend for their existence upon presently existing fundamentalia.

4.2 What if there are no derivative past objects?

But suppose that I'm wrong. Suppose that Cameron can show that, by his lights, the past objects aren't derivative as, for some reason, they aren't ontologically dependent upon present fundamentalia. What then? Then - or so I will argue - Cameron is committed to an unexplained necessary connection; a connection that we have some reason to think is objectionable.

We need to consider an objection to Cameron's view proposed by Jonathan Tallant and David Ingram (2012a) and Cameron's (2013) reply. Tallant and Ingram's (2012a: 308-9) concern runs as follows. Suppose that an object instantiates a TDP. It seems - say Tallant and Ingram - that it is possible for an object to change, such that it instantiate one TDP at one time, and another TDP at another time; they also claim that this is a problem for Cameron. To appreciate the shape of the problem, consider an example. Suppose that a rose instantiates the TDP, being-red-and-then-being-dead at $t_{1}$. It would be natural to suppose that, at $\mathrm{t}_{2}$, the rose instantiate the same property. According to Cameron, all that should change is that different portions of the property are now at the two times - the redness at $\mathrm{t}_{1}$, the deadness at $\mathrm{t}_{2}$. But as Tallant Ingram point out, it seems possible for the rose to change with respect to which TDP it instantiates. That is, it seems possible that the rose instantiate being-red-and-thenbeing-dead at $\mathrm{t}_{1}$, and being-green-and-then-being-dead at $\mathrm{t}_{2}$.

Cameron has recently replied to this concern. Here is the reply, in two parts. The first part notes that it is impossible for objects to change with respect to which TDPs it instantiates (2013: 366). All of which is well and good, but some explanation is required. Why is it impossible for the truthmakers to change in this way? Cameron's answer is that the age property an object has, together with its presently existing TDPs, ground facts about how objects have been, and will be. To give an example, that leans on our earlier presentation: the rose's age property, together with it instantiating the property being-red-and-then-being-dead, at $t_{1}$, makes it true that $<$ the rose won't change with respect to which TDP it instantiates>. The point, as Cameron sees things (2013: 370), is that TDPs fix the intrinsic natures over time. So of course, an object cannot change over time with respect to which TDP it instantiates; its intrinsic nature at those times has already been fixed.

Notice, then, the following: it is necessary that $\mathrm{x}$ not change the TDP that $\mathrm{x}$ instantiates. To illustrate, suppose that $\mathrm{t}$ is the present time. If $\mathrm{x}$, at $\mathrm{t}$, instantiates the TDP, $\mathrm{F}$, then $\mathrm{x}$, at $\mathrm{t} *$ instantiates the TDP, F. We have a necessary connection. Necessary connections, Cameron claims, are benign in some cases; non-benign in others. As we have seen, Cameron thinks that cases of necessary connection involving ontological dependence are benign. Again:

'necessary connections are perfectly explainable if the necessitating entity is ontologically dependent on the necessitated entity' (2008: 9)

We can now present Cameron with a dilemma. The first horn: this is a necessary connection that is to be explained by ontological dependence. In that case, Cameron will have to allow that non-present objects are ontologically dependent upon present objects and the TDP that they instantiate. This, as we have seen (3.1 and 3.2), is objectionable. The second horn: this is a necessary connection that is not explained by ontological dependence. 
Cameron himself cannot consistently take this line, for he is of the view that whenever there is a necessary connection, that connection is to be explained by the relation of ontological dependence that, in turn, is to be understood via the truthmaker commitments, outlined above (2010: 186). Of course, Cameron could rescind this claim. But dialectically this would be hard to motivate. The metaphysical picture being described by Cameron is a popular one. It is a broadly Humean metaphysic, according to which necessary connections are unlovely. Such connections are mysterious, and so to be rejected. And the only sense in which we've seen that these connections have been demystified is via Cameron's analysis of necessary connection.

That leaves us with two options, then. First, we could find some other way of explaining the necessary connections that would demystify them. I'm open to this possibility, but I know of no competing account that will succeed here. Second, then, we could argue that the kind of necessary connection invoked by the presentist is less threatening than the necessary connections described elsewhere in the literature, and that are taken to be problematic.

The second option strikes me as unlikely - though I don't want to say that it's impossible. In the case I described above, $\mathrm{x}$, at $\mathrm{t}$, instantiates the TDP, $\mathrm{F}$. This necessitates that, $\mathrm{x}$, at $\mathrm{t}^{*}$ instantiates the TDP, F. Now when $\mathrm{x}$-at-t is present, $\mathrm{x}$-at-t* does not exist. It is simply no part of reality. But we are now apparently committed to the claim that $\mathrm{x}$, at $\mathrm{t}$, has the capacity not only to constrain the nature of $\mathrm{x}$ at t*, but to necessitate its later existence.

Now in the presentist case there can be no relation connecting the non-present to the present. There can be no relation of necessitation to connect the present to the non-present because the non-present does not exist. This means that, although $\mathrm{x}$ 's instantiating $\mathrm{F}$ at $\mathrm{t}$ necessitates that $\mathrm{x}$ will exist at $\mathrm{t}^{*}$, and that $\mathrm{x}$ will instantiate $\mathrm{F}$ at $\mathrm{t}^{*}$, there cannot be an existing connection between $\mathrm{x}$ 's being $\mathrm{F}$ at $\mathrm{t}$, and $\mathrm{x}$ 's being $\mathrm{F}$ at $\mathrm{t}^{*}$.

This, I submit, threatens to make the necessary connection that the presentist requires doubly mysterious. Not only must they posit a necessary connection, a connection that we have some reason to reject in any case (in the sense that we are naturally suspicious of necessary connections), but they must also then deny that it really is a connection at all. The challenge that the presentist faces, then, is one of explaining how x's being $\mathrm{F}$ at $\mathrm{t}$, necessitates $\mathrm{x}$ 's being $\mathrm{F}$ at $\mathrm{t}^{*}$, without deploying any existing relations between $\mathrm{x}$ at $\mathrm{t}$ and $\mathrm{x}$ at $\mathrm{t} *$ in that explanation. That simply looks like a tall order. I don't say that the explanatory work cannot be done; I do say that it needs to be done.

I also say that it is difficult to see how it is to be done. For instance, one might normally look to explain a necessary connection as Cameron does. That has been ruled out. One might then look to posit a law of nature, that is a relation that connects to particulars, in order to give at least some account of why there is a necessary connection in place. This is ruled out, here, because we cannot invoke relations that connect these particulars (past particulars do not exist). Given the failure of these more typical strategies, it is very hard to see what is to be said.

\section{REFERENCES}

Armstrong, D. 2004. Truth and Truthmakers Cambridge: CUP

Baron, S. 2012. 'Presentism, Truth and Supervenience', Ratio, 26, 3-18

Baron, S. forthcoming. 'The Priority of the Now', Pacific Philosophical Quarterly, [DOI: 10.1111/papq.12030]

Bigelow, J. 1996. 'Presentism and Properties', Philosophical Perspectives, 10, 35-52

Bourne, C. 2002. 'When am I?', Australasian Journal of Philosophy, 80, 359-71

Bradon-Mitchell, D. 2004. 'How can we know it is now now?', Analysis, 64, 199-203

Button, T. 2006. 'There's no time like the present', Analysis, 66, 130-5

Cameron, R. 2008. 'Truthmakers and ontological commitment: or how to deal with complex objects and mathematical ontology without getting into trouble', Philosophical Studies, 140, 1-18

Cameron, R. 2010. 'From Humean Truthmaker Theory to Priority Monism', Nous, 44, 178-98 
Cameron, R. 2011. 'Truthmaking for presentists', Oxford Studies in Metaphysics, 6, 55-100

Cameron, R. 2013. 'Changing Truthmakers: reply to Tallant and Ingram', Oxford Studies in Metaphysics, 8, 362-373

Crisp, T. 2004. 'On Presentism and Triviality', Oxford Studies in Metaphysics, 1, 15-20

Markosian, N. 2004. 'A Defense of Presentism', Oxford Studies in Metaphysics, 1, 47-82

Markosian, N. 2010. 'Time.', In The Stanford Encyclopedia of Philosophy (Winter 2010 Edition), ed. E.N. Zalta. http://plato.stanford.edu/archives/win2010/entries/time/

Merricks, T. 2007. Truth and Ontology Oxford: OUP

Meyer, U. 2009. 'Times in Tense Logic', Notre Dame Journal of Formal Logic, 50, 201-219

Sanson, D and Caplan, B. 2010. 'The Way Things Were', Philosophy and Phenomenological Research, 81, 24-39

Tallant, J. 2009. 'Ontological Cheats Might Just Prosper', Analysis, 69, 422-30

Tallant, J. 2010. 'Still Cheating, Still Prospering', Analysis, 70, 5-206

Tallant, J. 2011. 'There's no future in no futurism', Erkenntnis, 74, 37-52

Tallant, J. 2014. 'Defining Existence Presentism', Erkenntnis, 79, 479-501

Tallant, J. and Ingram, D. 2012a. 'Presentism and Distributional Properties', Oxford Studies in Metaphysics, 7, 305-14

Tallant, J. and Ingram, D. 2012b. 'Time for Distribution?', Analysis, 72, 264-70

Zimmerman, D. 2008. 'The Privileged Present: Defending an "A-theory" of Time', in Sider, T. Hawthorne, J. and Zimmerman, D. eds. Contemporary Debates in Metaphysics Blackwell: Oxford, 211-225 